\title{
Ares I and Ares I-X Stage Separation Aerodynamic Testing*
}

\author{
Jeremy T. Pinier ${ }^{\dagger}$ and Charles J. Niskey ${ }^{\ddagger}$ \\ NASA Langley Research Center, Hampton, VA, 23681-2199
}

\section{Notice to Reviewers}

The Ares I and Ares I-X launch vehicles, including their predicted performance and certain other features and characteristics, have been defined by the U.S. Government to be Sensitive But Unclassified (SBU). Information deemed to be SBU requires special protection and may not be disclosed to an international audience, such as the audience sure to be present at the 2011 Aerospace Sciences Meeting. To comply with SBU restrictions, details have been removed from some plots and figures in this abstract. It is the opinion of the authors that despite these alterations, there is no loss of meaningful technical content. Analytical methodologies and capabilities are discussed; significant and interesting technical results are obvious and still present; and meaningful conclusions are still present.

The aerodynamics of the Ares I crew launch vehicle (CLV) and Ares I-X flight test vehicle (FTV) during stage separation was characterized by testing 1\%-scale models at the Arnold Engineering Development Center's (AEDC) von Karman Gas Dynamics Facility (VKF) Tunnel A at Mach numbers of 4.5 and 5.5. To fill a large matrix of data points in an efficient manner, an injection system supported the upper stage and a captive trajectory system (CTS) was utilized as a support system for the first stage located downstream of the upper stage. In an overall extremely successful test, this complex experimental setup associated with advanced postprocessing of the wind tunnel data has enabled the construction of a multi-dimensional aerodynamic database for the analysis and simulation of the critical phase of stage separation at high supersonic Mach numbers. Additionally, an extensive set of data from repeated wind tunnel runs was gathered purposefully to ensure that the experimental uncertainty would be accurately quantified in this type of flow where few historical data is available for comparison on this type of vehicle and where Reynolds-averaged Navier-Stokes (RANS) computational simulations remain far from being a reliable source of static aerodynamic data.

\section{Nomenclature}

\section{Symbols}

$\alpha \quad$ upper stage angle of attack, deg

$\beta \quad$ upper stage sideslip angle, deg

$\Delta \alpha \quad$ relative angle of attack between the upper and first stage, deg

$\Delta \beta \quad$ relative sideslip angle between the upper and first stage, deg

$\Phi \quad$ azimuthal position of the first stage separation relative to the upper stage

$D \quad$ reference diameter, diameter of the first stage solid rocket booster, $i n$.

$L \quad$ length of the vehicle, model scale, $i n$.

$M \quad$ Mach number

$P \quad$ pressure, $l b / i n .^{2}$

$Q \quad$ freestream dynamic pressure, $l b / f t^{2}$

Re Reynolds number based on first stage diameter.

$x \quad$ distance along model centerline, zero at tip of the launch abort tower, $i n$.

$X_{\text {sep }} / D$ downstream separation distance between the first and upper stages

$Y_{\text {sep }} / D \quad$ lateral separation distance between the first and upper stages

$Z_{\text {sep }} / D \quad$ vertical separation distance between the first and upper stages

$R_{\text {sep }} / D$ radial separation distance between the first and upper stages

\footnotetext{
* Submitted to the ARES invited session

${ }^{\dagger}$ Research Aerospace Engineer, Configuration Aerodynamics Branch, MS 499, Senior Member AIAA.

${ }^{\ddagger}$ Aerospace Engineer, Black Ram Engineering, Senior Member AIAA.
} 


\section{Acronyms}

$\begin{array}{ll}\text { AEDC } & \text { Arnold Engineering Development Center } \\ \text { AMS } & \text { angle measurement system } \\ \text { BDM } & \text { booster decelerator motor } \\ \text { BMC } & \text { balance moment center } \\ \text { BTM } & \text { booster tumbling motor } \\ \text { CFD } & \text { computational fluid dynamics } \\ \text { CLV } & \text { crew launch vehicle } \\ \text { CTS } & \text { captive trajectory system } \\ \text { DOF } & \text { degrees of freedom } \\ \text { FS } & \text { first stage } \\ \text { FTV } & \text { flight test vehicle } \\ \text { GNC } & \text { guidance, navigation and control } \\ \text { LAS } & \text { launch abort system } \\ \text { OML } & \text { outer mold line } \\ \text { RANS } & \text { Reynolds averaged Navier-Stokes } \\ \text { RoCS } & \text { roll control system } \\ \text { SRB } & \text { solid rocket booster } \\ \text { SRP } & \text { separation plane } \\ \text { US } & \text { upper stage }\end{array}$

\section{Forces and Moments}

$\begin{array}{ll}\text { CAF } & \text { axial force coefficient, } C_{A} \\ \text { CRM } & \text { rolling moment coefficient, } C_{l} \\ \text { CSF } & \text { side force coefficient, } C_{Y} \\ \text { CYM } & \text { yawing moment coefficient, } C_{n} \\ \text { CNF } & \text { normal force coefficient, } C_{N} \\ \text { CPM } & \text { pitching moment coefficient, } C_{m}\end{array}$

\section{Introduction}

The Ares I crew launch vehicle is an in-line, two-stage vehicle, with a solid rocket booster (SRB) as a first stage inherited from the Space Shuttle boosters and modified with an added fifth segment. The upper stage consists of the launch abort system (LAS), the crew module (CM), the service module (SM), the spacecraft adapter (SA), and the liquid oxygen (LOX) and liquid hydrogen $\left(\mathrm{LH}_{2}\right)$ tanks that provide oxidizer and fuel for the $\mathrm{J} 2-\mathrm{X}$ main engine. The first and upper stages are connected by the interstage, characterized by a diameter change from the large upper stage to the smaller first stage solid rocket booster diameter. One of the most critical and dynamic phases of the Ares I flight is the stage separation event at around $M=5.5$, where the first stage (FS) separates from the upper stage (US) using booster decelerator motors (BDM) until it reaches a safe separation distance where the booster tumbling motors (BTM) fire to force the FS to tumble in its descent for a greater deceleration. Stage separation aerodynamics presents many challenges for its characterization and modeling. Indeed, the physics of the flow are very complex and present a harsh environment for steady measurements. It is characterized by a high supersonic flow, a turbulent wake behind the US, bow shock interactions and impingements on the FS, as well as high angles of attack and sideslip. This combination of flow physics makes for an extremely challenging computational simulation using codes that employ Reynolds-averaged Navier-Stokes (RANS) solvers. RANS is indeed not suited for highly unsteady separated and wake flows. Wind tunnel testing is therefore indispensable to gather aerodynamic data in great quantities on such vehicles and test conditions. The aerodynamic testing was completed at the AEDC VKF Tunnel A that is equipped with a captive trajectory system (CTS), capable of autonomously and efficiently acquiring a large matrix of data points. The main points of concern during stage separation are: 1) the possibility of re-contact between the separated stages, 2) on Ares I, the FS front end "open-cup" geometry clearing the US main engine nozzle, and 3) accurately predicting the FS steady forces and moments while in the turbulent wake of the upper stage. The present paper describes the test setup, a selected sample of results, a description of the data post-processing for creating a complete and consistent aerody- 
namic database and the uncertainty analysis methods that were used to capture all variations in the measurements, as well as general lessons learned related to stage separation testing for this type of launch vehicle.

\section{A. The Ares I crew launch vehicle and Ares I-X flight test vehicle}
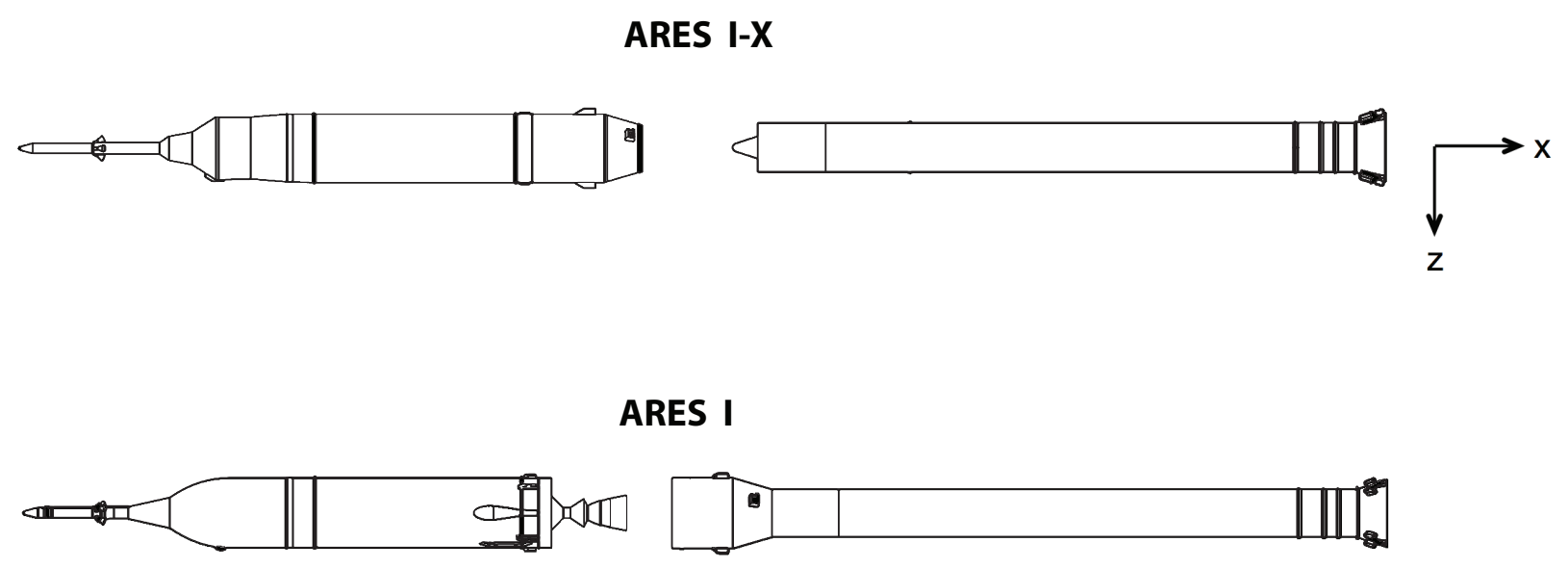

Figure 1. Ares I-X flight test vehicle and Ares I crew launch vehicle, illustrating the different stage separation planes, drawing not to scale.

The geometry and outer mold line (OML) of the Ares I-X FTV had to be fixed early-on in the development of the Ares I vehicle to enable design, fabrication, and testing of the equipment as part of the Ares I-X flight test that occurred on October 28, 2009 at the Kennedy Space Center. Ares I has seen significant geometry changes over the last design cycles, primarily driven by aeroacoustics and subsystems placement. The most striking OML changes are: 1) Ares I has a modified ogive shape crew module fairing as opposed to the bi-conical shaped crew module fairing on Ares I-X, 2) the separation plane is located upstream of the interstage for Ares I, rather than behind the frustum area, at the top of the first stage booster for Ares I-X, 3) there are $10 \mathrm{BDMs}$ on Ares I compared to 8 on Ares I-X, and 4) the BTMs are located on the frustum on Ares I and on the aft skirt on Ares I-X. Figure 1 illustrates the main aforementioned geometrical differences between the Ares I and Ares I-X geometries.

\section{B. The AEDC VKF Tunnel A}

The AEDC VKF Tunnel A is a closed circuit continuous flow variable pressure supersonic facility. The tunnel contains three test sections with Mach numbers ranging from 1.5 to 10. Tunnel A has a 40-inch square test section and a symmetric, computer controlled, continuous-curvature nozzle that can vary Mach number from 1.5 to 5.5. Tunnel B has a 50-inch test section and hypersonic capabilities of $M=6$ and $M=8$. Tunnel $\mathrm{C}$ has a hypersonic test section with Mach numbers of 4, 6 and 10 and offers the capability of providing aerothermal environments of up to $1440^{\circ} \mathrm{F}$. A detailed report about tunnel performance and operational characteristics was elaborated by Boudreau ${ }^{1}$

\section{Captive trajectory force and moment test setup}

\section{A. Model and support system description}

Both Ares I and Ares I-X models were $1 \%$ of full scale size for a total length of around 40 inches and the diameter of the first stage was used as a reference length, $D$, measuring around 1.5 inches. This size was large enough to be able to manufacture the small protuberances on the outside of the model, and small enough to be able to get high fidelity data in a 40-inch test section wind tunnel, avoiding any significant blockage and wall interference effects. The models were primarily built from aluminum to limit the weight and therefore minimize the effects of oscillations and vibrations when subject to the flow. Stainless steel was used for the high-precision parts like the balance blocks, by which the models are mounted to the balance. The dynamics of the models were monitored during testing to prevent any overloading of the balance gages. Every external protuberance was removable (except for any axisymmetric stiffener ring or local diameter change) to enable testing of the clean configuration (i.e. axisymmetric, no protuberance 
installed). The majority of testing was completed on the clean configuration to take advantage of symmetry and fill a larger database by appropriately mirroring the data. This post-processing method is described in Section III. The clean configuration was assumed axisymmetric, even though the LAS tower exhibits four launch abort motor nozzles. Discrepancies due to non-axisymetry were measured and included in the uncertainty analysis.
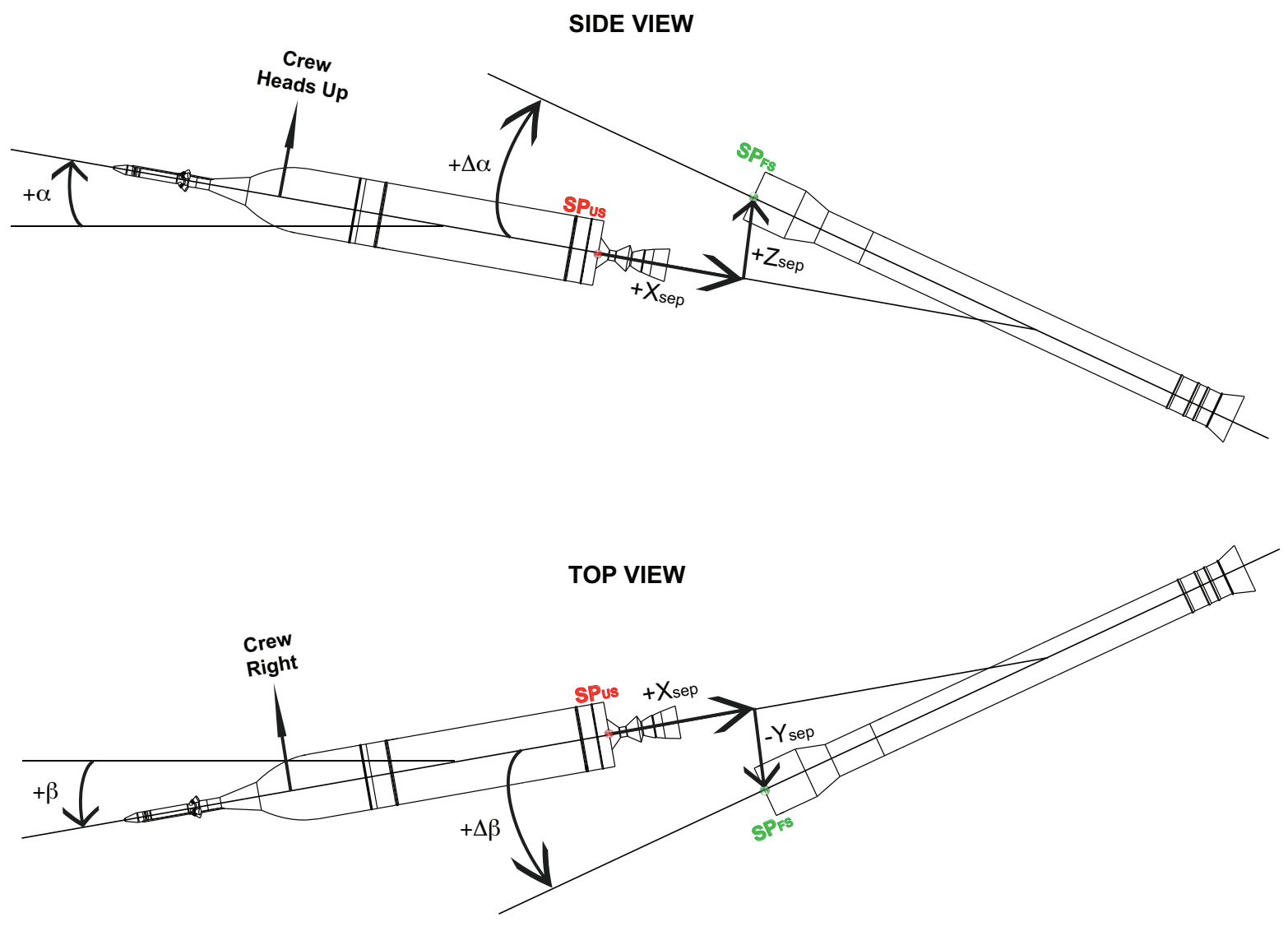

Figure 2. Angle and separation distance definitions.

Figure 2 shows a schematic defining the angles and separation distances between the US and FS. The conditions and ranges of attitudes tested are described in Table A.

The Reynolds numbers tested were on the same order of magnitude as flight Reynolds numbers, however boundary layer trips were still used to ensure early transition to turbulence. Finding the most effective way of tripping the boundary layer is a challenge on slender bodies of revolution. After an investigation into that matter ${ }^{2}$ and using various transition grit patterns and qualitative diagnostic techniques such as sublimation, it was concluded that several circumferential grit strips with heights tailored to the Mach number range and applied to the upper portion of the models would be sufficient to force transition to turbulence on the surface of the vehicle. However this topic remains an open question and deserves further in-depth investigations if transition to turbulence showed up as a large factor in the measurement uncertainties. None of the data collected thus far has shown significant sensitivity to the gritting strategy.

The VKF Tunnel at AEDC is equipped with a 6-DOF captive trajectory system (CTS) that traditionally enables testing of store separation on military aircraft. In the present case the CTS was used to support the first stage and displace and/or rotate it with respect to the upper stage. Table A shows the range of motion of the upper stage, which was only pitched at fixed increments $\left(0^{\circ}, 2^{\circ}, 5^{\circ}\right.$, and $\left.10^{\circ}\right)$. Since the models are mounted in an inverted position in the tunnel, a positive pitch angle $\alpha$ means the nose of the upper stage pitches down. The table also shows the range of displacement and rotation of the first stage with respect to the upper stage, with $\Delta \alpha$ and $\Delta \beta$ being the relative angles of attack and sideslip of the FS. Each run was performed with the upper stage at a static attitude $\alpha$ and the first stage performing a longitudinal sweep downstream of the upper stage, parallel to the upper stage longitudinal axis at a given combination of $X_{\text {sep }} / D, R_{\text {sep }}, \Delta \alpha$ and $\Delta \beta$. Over the course of the test, over 4,400 such runs were performed for a total of nearly 35,000 data points. 


\begin{tabular}{|l|l|l|}
\hline Parameter & Ares I-X & Ares I \\
\hline \hline Mach number & 4.5 & 5.5 \\
\hline Temperature & $150^{\circ} \mathrm{F}$ & $220^{\circ} \mathrm{F}$ \\
\hline Reynolds number & $0.47 \times 10^{6}$ & $0.24 \times 10^{6}$ \\
\hline Dynamic pressure & $457 \mathrm{lb} / \mathrm{ft}^{2}$ & $145 \mathrm{lb} / \mathrm{ft}^{2}$ \\
\hline$\alpha$ (upper stage) & $0^{\circ}, 2^{\circ}, 5^{\circ}, 10^{\circ}$ & $0^{\circ}, 2^{\circ}, 5^{\circ}$ \\
\hline$X_{\text {sep }} / \mathrm{D}$ & $0.171-10.542$ & $0.171-10.542$ \\
\hline$R_{\text {sep }} / \mathrm{D}$ & $0-2$ & $0-2$ \\
\hline$\Delta \alpha$ (first stage) & $0^{\circ},-5^{\circ}, 5^{\circ}$ & $0^{\circ},-5^{\circ}, 5^{\circ}, 10^{\circ}, 15^{\circ}$ \\
\hline$\Delta \beta$ (first stage) & $0^{\circ},-5^{\circ}, 5^{\circ}$ & $0^{\circ},-5^{\circ}, 5^{\circ}$ \\
\hline
\end{tabular}

Table A. Wind tunnel conditions and model attitude ranges tested

The upper stage was strut-mounted and connected to an injection system that lowers below the test section in a depressurized tank to enable model changes without having to interrupt the flow in the tunnel. Before being injected in the flow, the tank is closed, sealed and re-pressurized to tunnel conditions, followed by an opening of the tunnel floor and injection of the model in the freestream flow. During these operations, the CTS system supporting the first stage is located at a safe position downstream and opposite of the floor opening to prevent the balance from experiencing dynamics as the upper stage model is being injected. Figures 3 and 4 show both first and upper stages in the VKF Tunnel A test section for Ares I and Ares I-X.

\section{B. Instrumentation}

The models were mounted on 6-component internal strain gage balances, with the balance moment center (BMC) approximately placed around the expected center of pressure. The first stage balance was mounted inverted, frontend forward on a slender stainless steel (Vascomax) sting. The upper stage balance was mounted inverted, back-end forward on the strut. The balances used were recently calibrated direct-read Langley balances and were chosen to fit the expected loads during testing. The model being a very slender launch vehicle and not having lifting surfaces, rolling moment was expected to be small. The measured rolling moments during the tests still were small relative to the full scale allowable load for these balances. Only a small part of the calibrated range of the balance was utilized, which partly explains the higher uncertainties experienced in the rolling moment results. More details on this topic are discussed by Pinier ${ }^{3}$. Best practices related to the calibration and use of internal strain gage balances as described by the AIAA Recommended Practices ${ }^{4}$ were consistently followed during testing.

Base pressure was measured on the first stage to compute a base force coefficient and in turn a fore-body axial force coefficient. Two static pressure tubes were run inside the sting and mounted close to the base of the internal balance to measure cavity pressure. Four pressure tubes were also run externally along the sting to measure the base pressure. Kulite sensors mounted inside the CTS were used to perform these measurements. The six measurements are averaged and multiplied by the base surface area to provide a base drag that is subtracted from the measured axial force to result in the fore-body axial force.

A fouling strip was installed around the sting at the aft end of the model to indicate the occurrence of any excessive longitudinal rotation of the model with respect to the sting due to aerodynamic loads that would make the back end foul the sting, in which case the measurements would be corrupted. Additionally, both models were connected to a grounding circuit that is triggered as soon as either both models come into contact or one of them makes contact with a tunnel wall. For this purpose, all parts of the models need to be electrically conductive.

Schlieren flow visualization video was also acquired to investigate the effect of upper stage shock impingement on the first stage, as well as shock interactions in the wake of the upper stage. The implementation of Schlieren was crucial in the investigation of a shock-wake interaction that occurred during Ares I-X testing and that resulted in seemingly larger-than-normal discrepancies in repeat runs. This topic is discussed in the following section. 


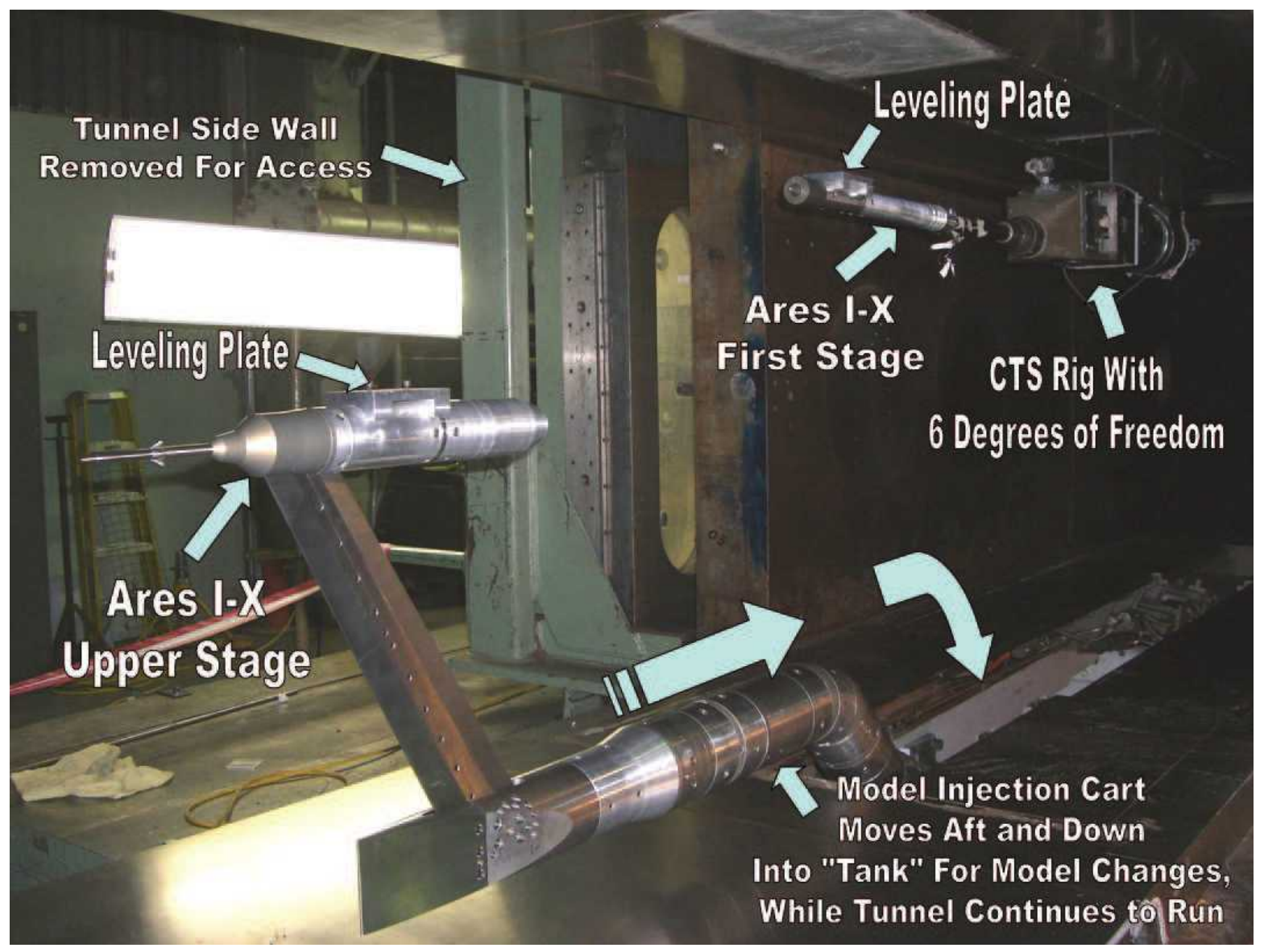

Figure 3. Ares I-X model with upper stage mounted on injection system and first stage mounted on the 6-DOF CTS system.

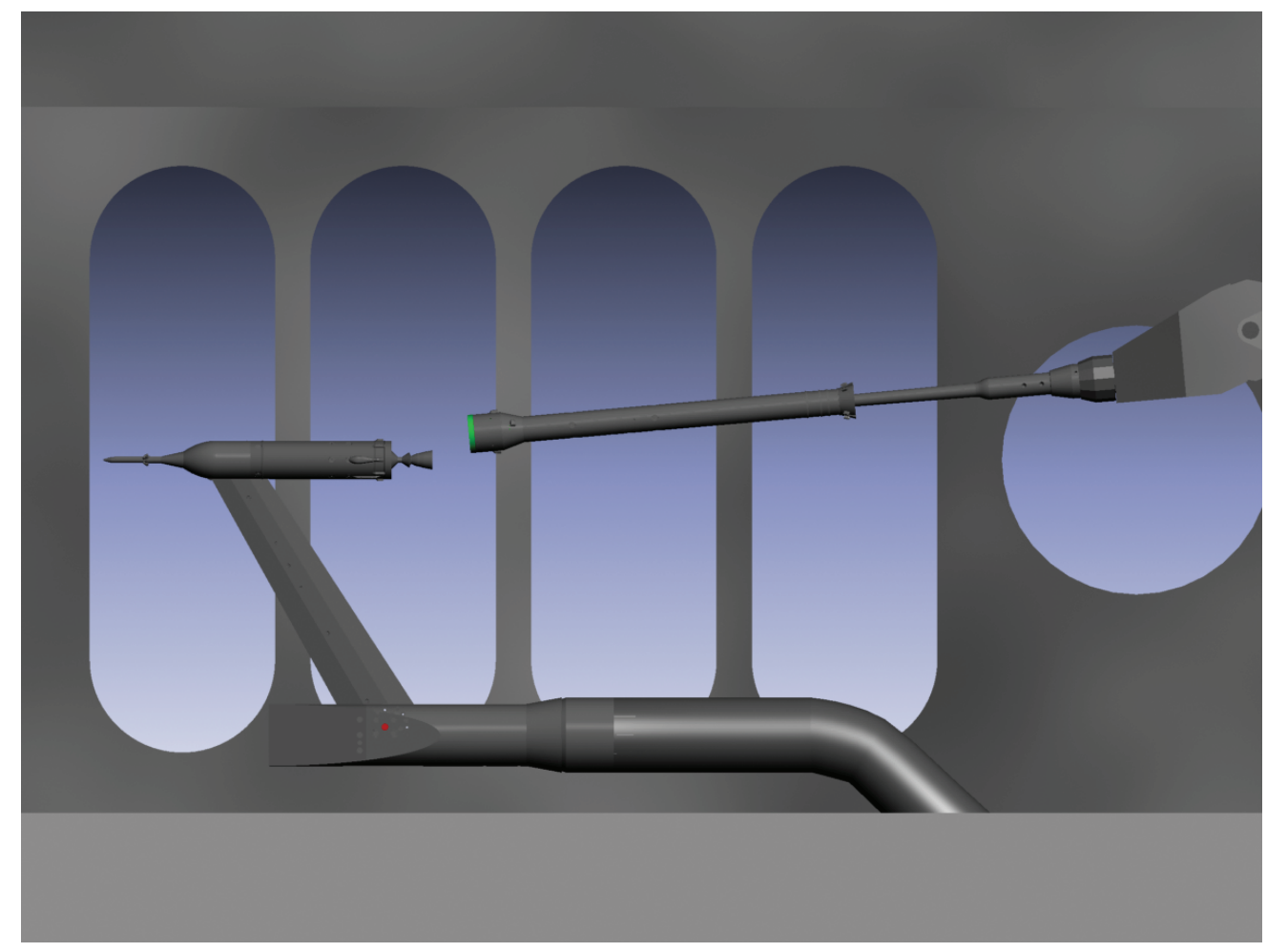

Figure 4. Rendering of the Ares I model in the VKF Tunnel A test section. 


\section{Results}

\section{A. Test matrix}

The test matrix was designed to enable a large amount of data to be acquired with both vehicles in very close proximity, where the highest gradients in the data were expected. It is crucial to capture the correct physics in this area to accurately predict whether the vehicles could eventually re-contact following the stage separation event, and whether or not dynamics due to unsteady aerodynamic forces could be a problem. At larger separation distances, the data was not required in a fine spatial resolution. A much sparser set of data was therefore taken as $X_{\text {sep }} / D$ increased. For each discrete US attitude $\left(0^{\circ}, 2^{\circ}, 5^{\circ}\right.$ and $\left.10^{\circ}\right)$, a set of downstream sweeps was performed at various combinations of first stage radial positions and attitudes relative to the upper stage. Figures 5, 6 and 7 show the spacial extent of the data set acquired in the wind tunnel.

\section{B. Data quality and uncertainty quantification}

Data quality and consistency were ensured during the entire length of the test by performing daily check-loads on both balance/model assemblies in the test section, as well as daily tare-checks to ensure that the weight of the models is computed accurately and subtracted from the total loads in a correct fashion. Consistency with the results from the initial build-up of the setup in the controlled environment of the calibration laboratory is also checked during these daily checks.

Repeatability assessments were performed at regular intervals during the test and were of two different types:

1. A reference set of runs was performed initially and then at regular intervals during the test to ensure data consistency throughout the duration of the test. This was in particular important since this test covered a 6 week period. Any unexpected change in flow quality or any balance issue would be uncovered during these repeat runs and investigated before any additional production runs were performed. Several critical issues were found during these reference runs, some of which are discussed in Section IV.

2. Uncertainty assessment repeat runs were also performed throughout the test to capture the dependency of data repeatability with all the variables. During post-processing, statistical methods are used to quantify repeatability ${ }^{5}$. It is therefore important to gather repeat data at all attitudes and flow conditions to detect any correlation in the residuals, in which case a higher fidelity uncertainty model can be built using this information.

Figures 8 and 9 respectively show upper and first stage forces and moments for a set of seven repeat runs performed at various times during the test. For all of these runs the Ares I upper stage is at $\alpha=0$ and the first stage is traversed downstream directly behind the upper stage with $\Delta \alpha=\Delta \beta=0$ and $R_{\text {sep }} / D=0$. Naturally, in this configuration all forces and moments are very close to zero for both upper and first stages except for axial force. The first stage is shielded by the upper stage in a low drag configuration up to a separation distance of $X_{\text {sep }} / D=4.5$ where the recirculation region closes and the first stage is more and more exposed to the freestream flow, characterized by a sharper increase in drag. The upper stage experiences lower drag when the first stage is in close proximity and as long as the front end of the first stage remains in the recirculation region, increasing base pressure on the upper stage and therefore decreasing its drag.

It is also seen in this figure that the major variability between repeat runs manifests itself as biases or shifts. The criterion used for accepting variations observed during repeat runs was $0.25 \%$ of balance full scale limits. These shifts however are most of the time equal to or smaller in magnitude than the balance calibration error plotted as an error bar on the last point of the average of the repeat runs. These biases are most likely explained by balance zero shifts

due to the temperature gradients experienced during testing. It was found that the two main sources of experimental measurement uncertainty during this test were dominated by balance zero shifts as well as CTS positional precision and accuracy.

\section{Data post-processing}

A significant amount of data post-processing was required to develop a consistent database characterizing stage separation aerodynamics. Indeed, most of the data was taken on the clean (axisymmetric) configuration of the models. Data was however taken at all azimuthal positions of the first stage relative to the upper stage, as shown in Fig. 6. Symmetry was therefore used to: 1) force the data to be consistent, thereby subtracting any systematic error (or bias) present in the measurements, 2) measure and eliminate effects of the US strut wake on the first stage, 3) capture a 


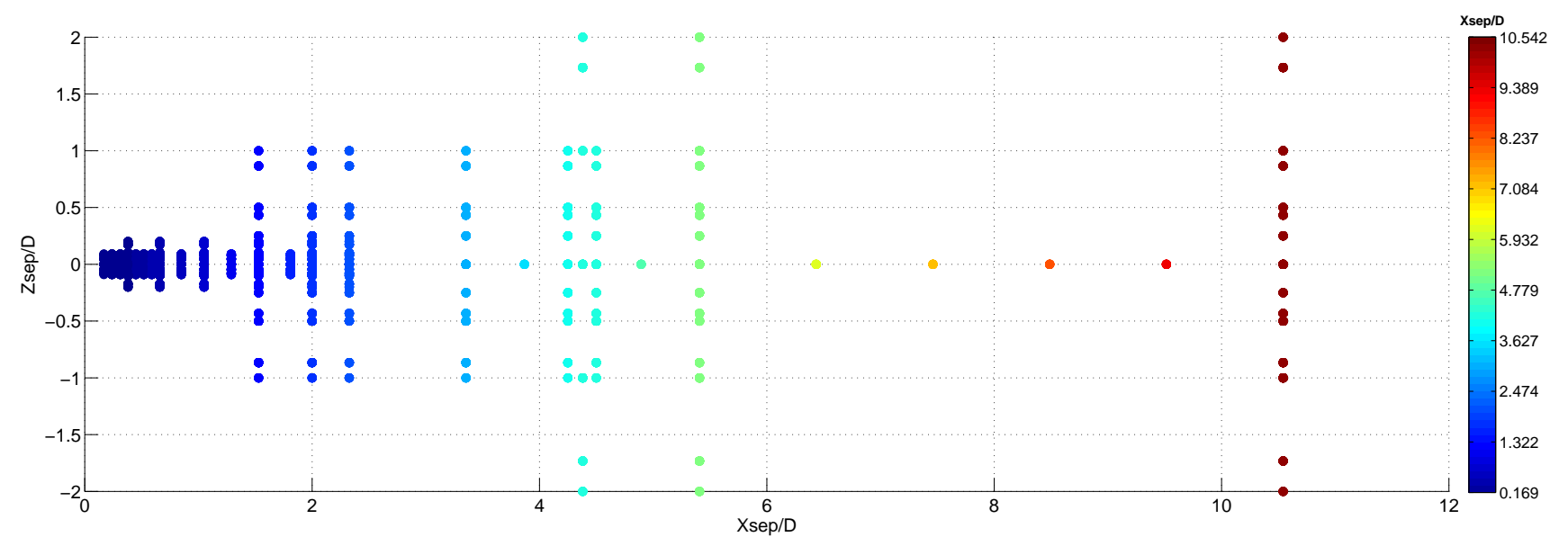

Figure 5. Matrix of spatial points where data was acquired at all combinations of $R_{s e p} / D, \Delta \alpha$, and $\Delta \beta .\left(X_{s e p} / D, Z_{s e p} / D\right)$ view.

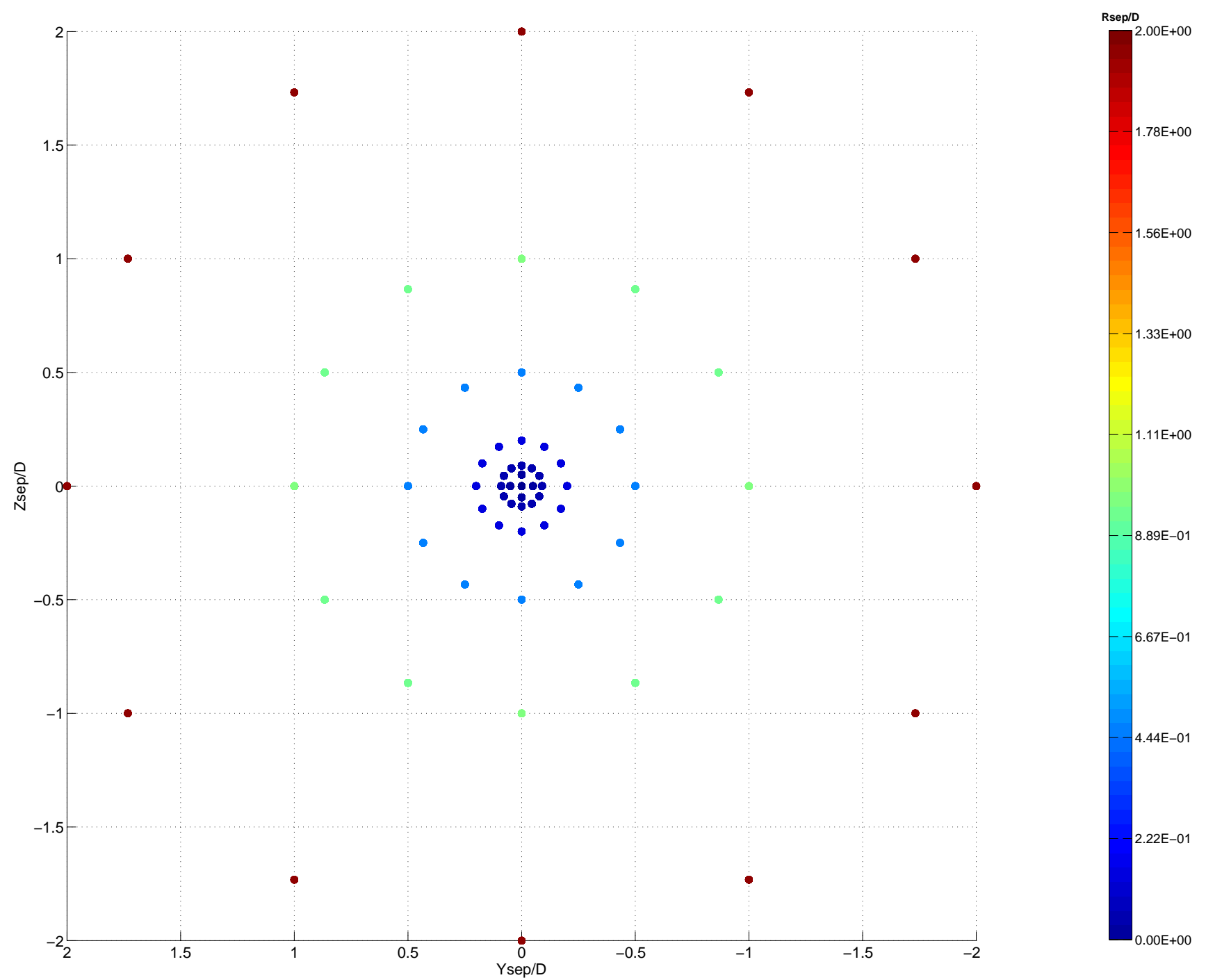

Figure 6. Matrix of spatial points where data was acquired at all combinations of $R_{\text {sep }} / D, \Delta \alpha$, and $\Delta \beta$. $\left(Y_{\text {sep }} / D, Z_{\text {sep }} / D\right)$ view. 


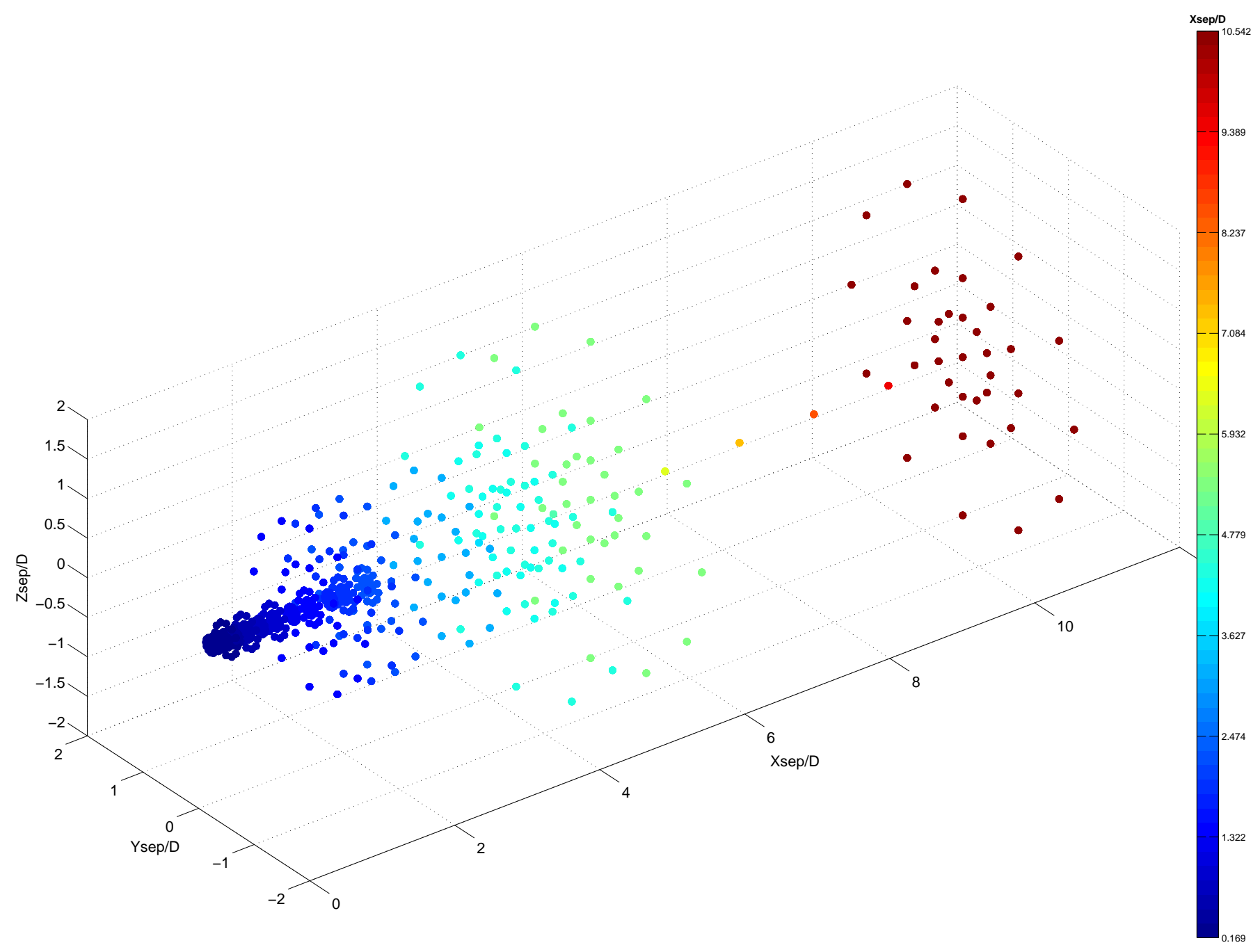

Figure 7. Matrix of spatial points where data was acquired at all combinations of $R_{s e p} / D, \Delta \alpha$, and $\Delta \beta .\left(X_{s e p} / D, Y_{s e p} / D, Z_{s e p} / D\right)$ view. 

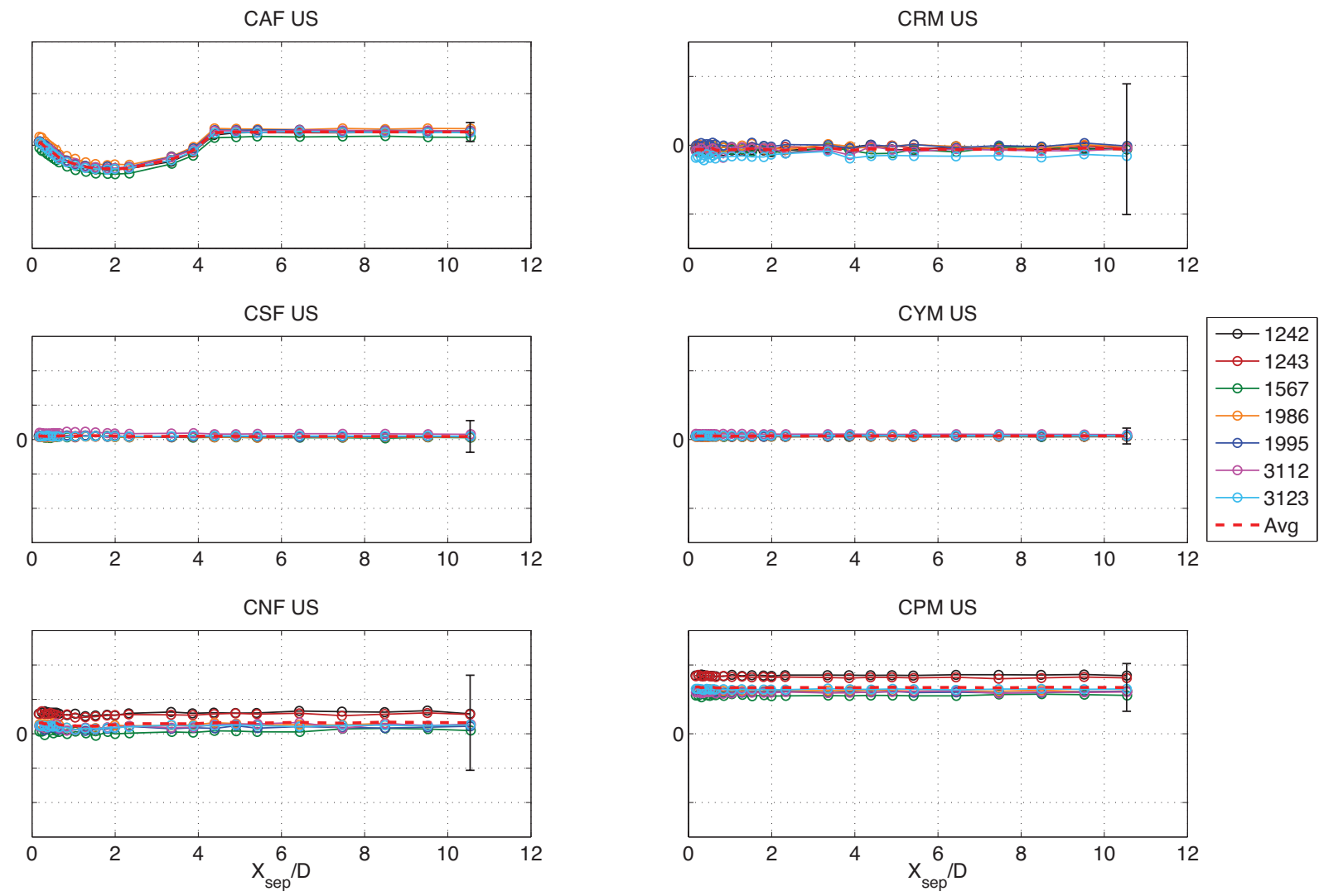

Figure 8. Ares I-X upper stage forces and moments for 7 repeat runs, with average (red dashed) and balance calibration accuracy (error bars) for each component.
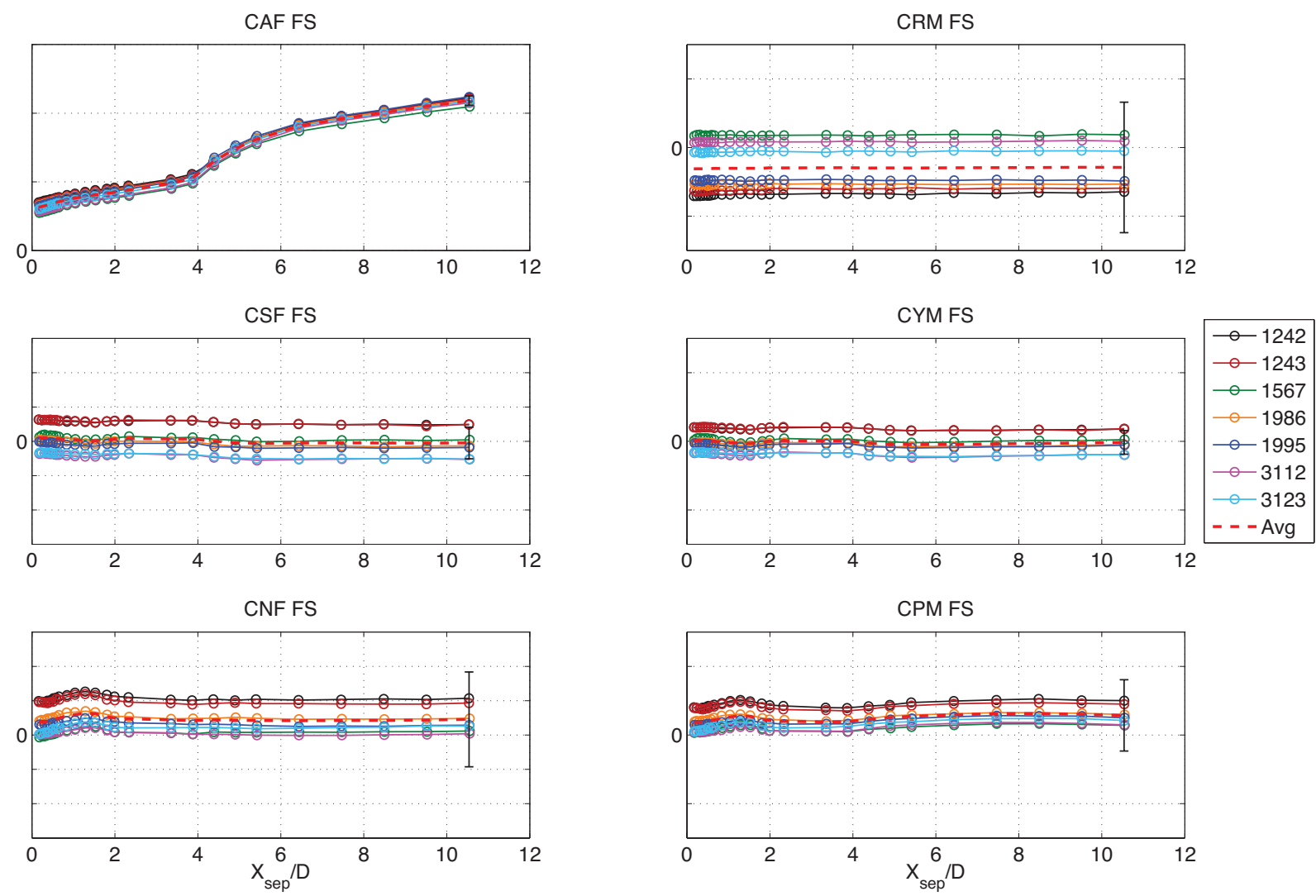

Figure 9. Ares I-X first stage forces and moments for 7 repeat runs, with average (red dashed) and balance calibration accuracy (error bars) for each component. 

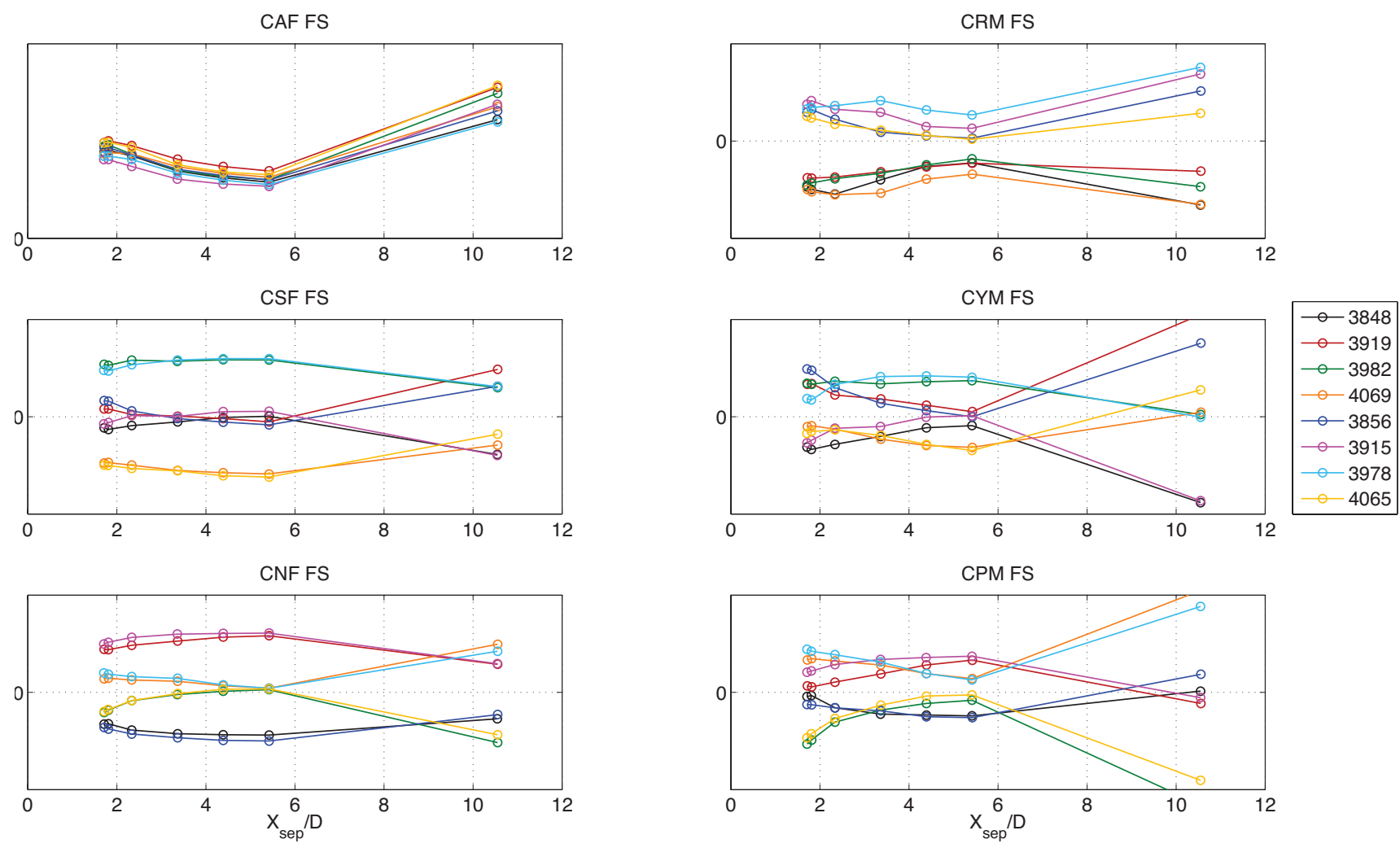

Figure 10. Ares I first stage force and moment data in the vertical-plane axis system.
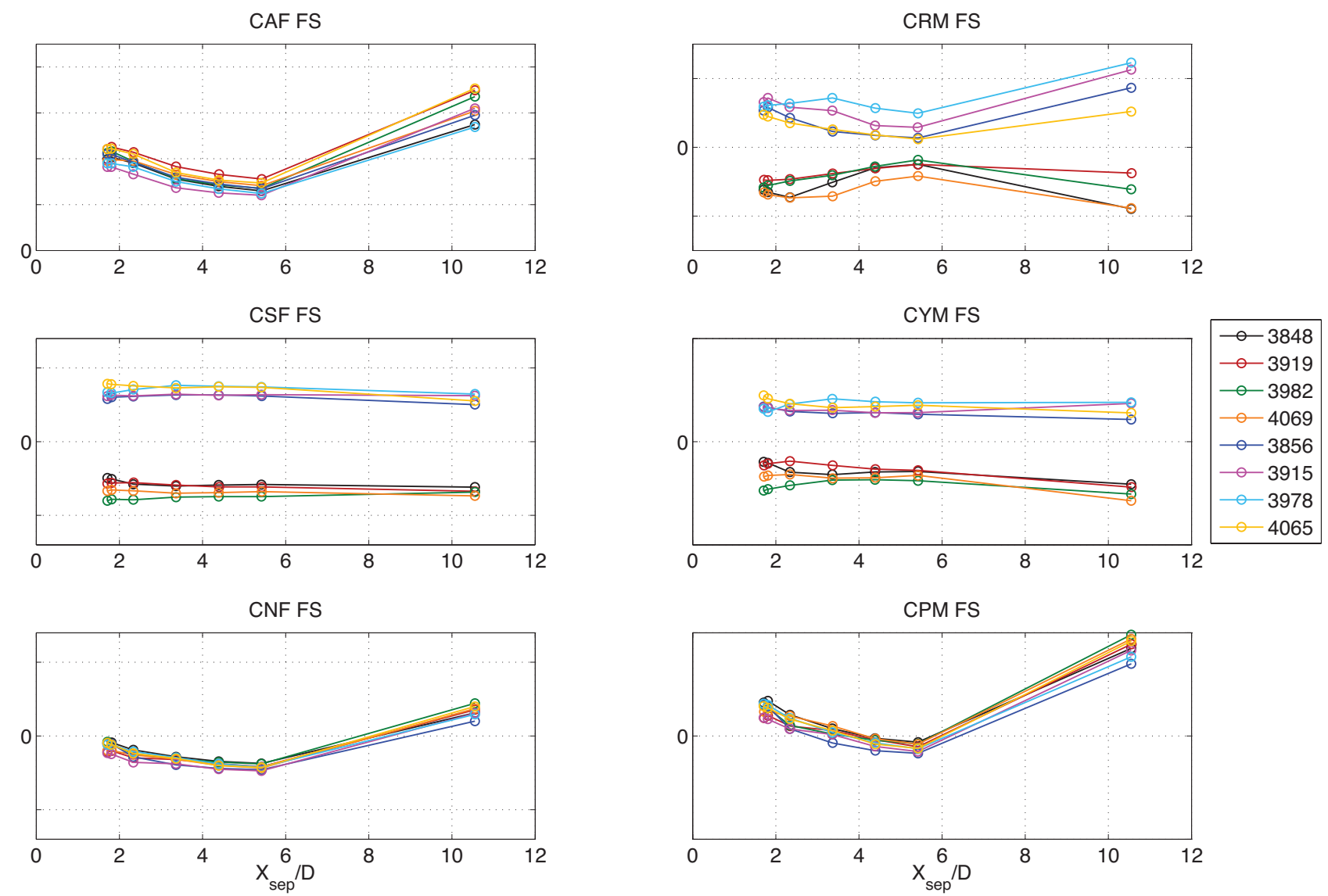

Figure 11. Ares I first stage force and moment data in the polar axis system as defined in Eq. 1. 

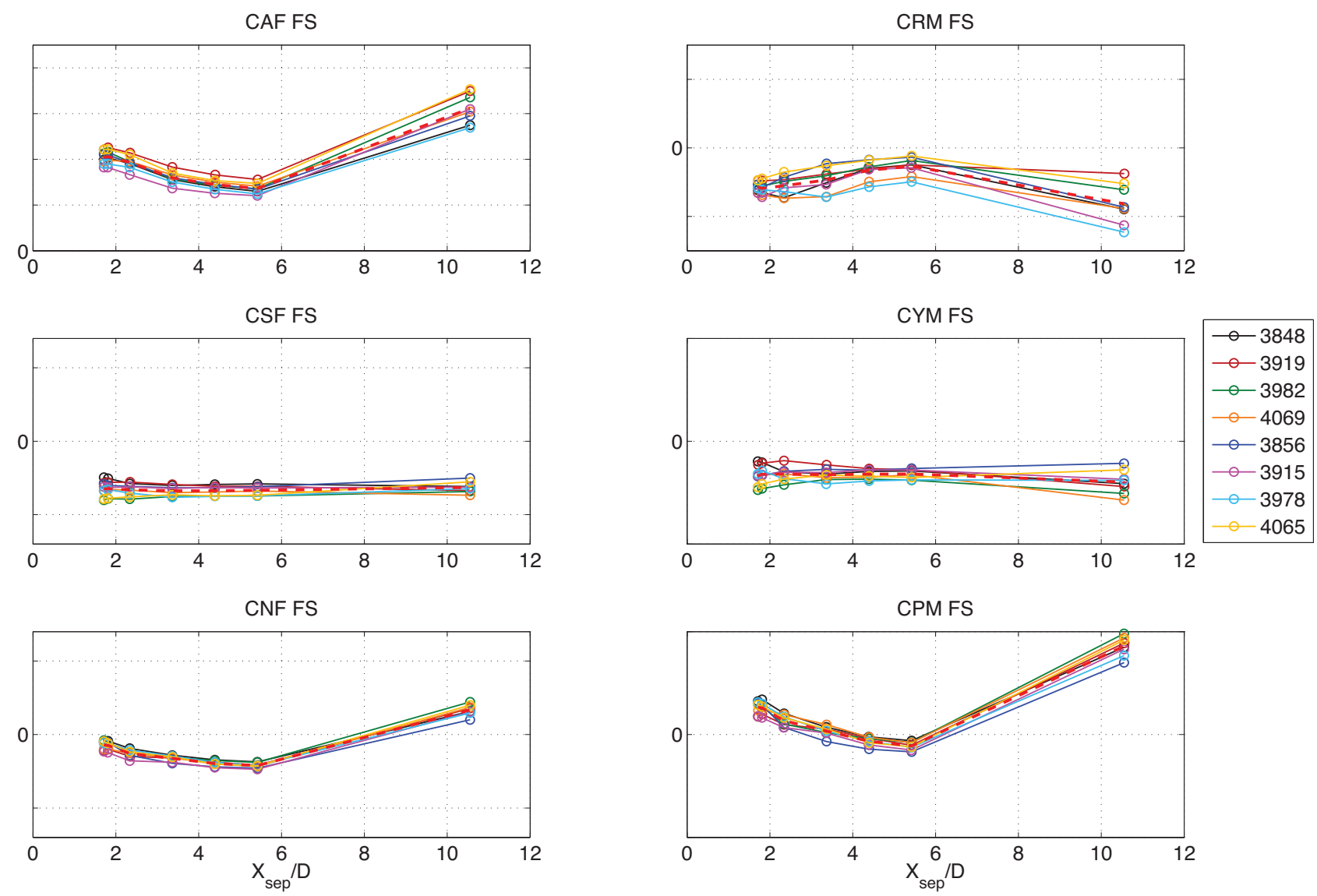

Figure 12. Ares I first stage force and moment data in the polar axis system, mirrored to collapse, and averaged (red dashed line).
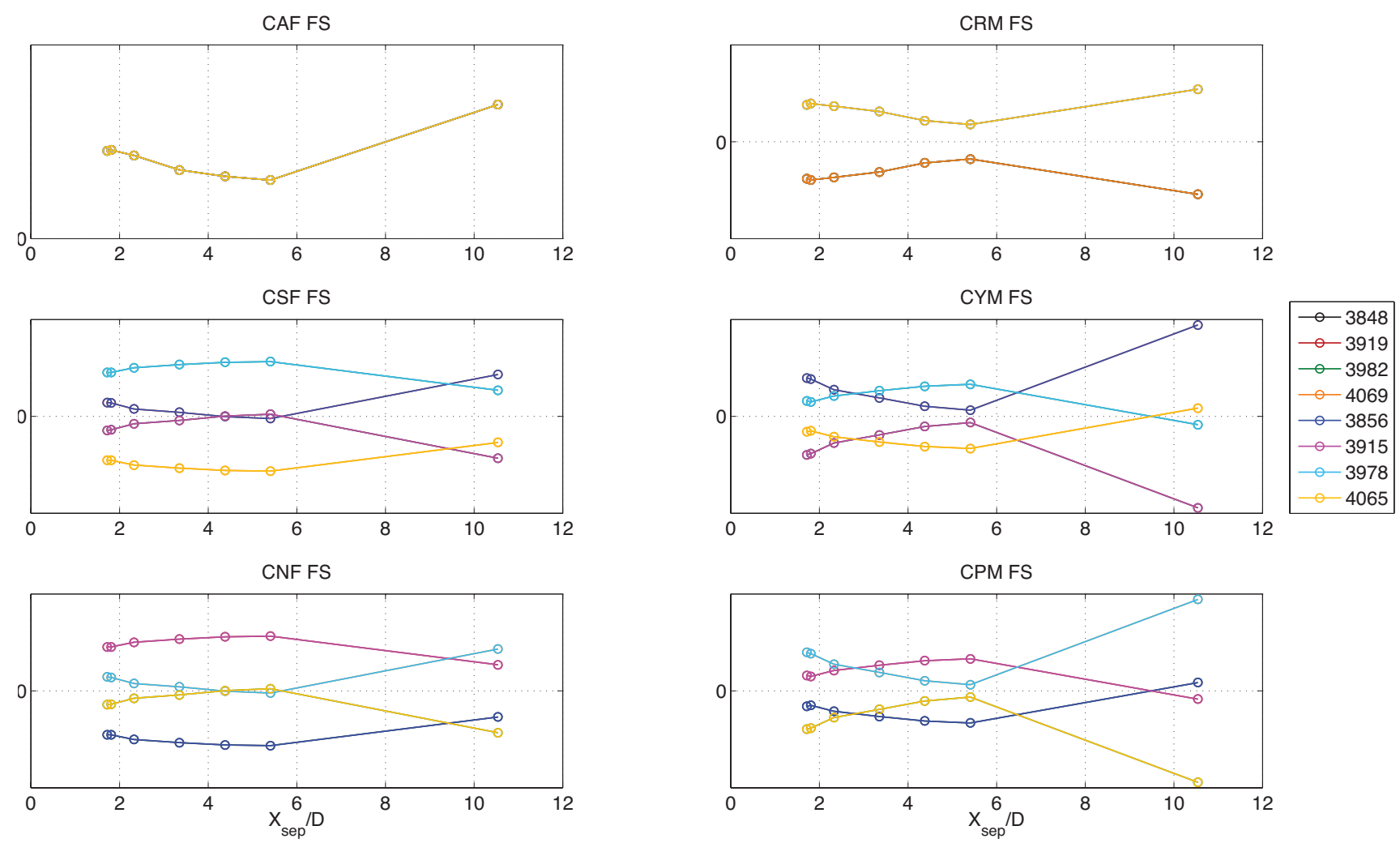

Figure 13. Ares I first stage force and moment data in the vertical-plane axis system, at nominal conditions. 
better estimate of the uncertainty due to repeatability at different locations in the tunnel, and 4) fill the matrix where data was missing. A detailed example of data post-processing is illustrated by Figures 10 to 13. The figures show eight first stage sweeps performed downstream of the upper stage at $\alpha=0$, and with $R_{\text {sep }} / D=1$, and $[\Delta \alpha, \Delta \beta, Y$ sep $/ D$, $\left.Z_{\text {sep }} / D\right]$ combinations chosen such that the first and upper stages are at the same relative angle from one another in all runs, but at different locations in the tunnel. The process of finding all runs among the 4400 runs that are geometrical repeats from one another was performed automatically. Figure 10 shows the forces and moments in the vertical-plane axis system for a set of eight geometrical repeats. The following steps were typically followed to correct this data set:

1. Each complete set of runs should be evenly distributed around zero for all forces and moments except for rolling moment. Any bias was quantified and subtracted from all runs to center the data around zero.

2. The data is then transformed from the vertical-plane axis system (subscript $v$ ) to the polar axis system (subscript $p$ ) using the following equations, and as illustrated by Fig. 11:

$$
\begin{aligned}
C_{A, p} & =C_{A, v} \\
C_{l, p} & =C_{l, v} \\
C_{Y, p} & =C_{Y, v} \cos (\Phi)-C_{N, v} \sin (\Phi) \\
C_{N, p} & =C_{N, v} \cos (\Phi)+C_{Y, v} \sin (\Phi) \\
C_{n, p} & =C_{n, v} \cos (\Phi)-C_{m, v} \sin (\Phi) \\
C_{m, p} & =C_{m, v} \cos (\Phi)+C_{n, v} \sin (\Phi)
\end{aligned}
$$

3. The side force and yawing moment data in the polar axis system is then mirrored according to the sign of the relative angle between the first stage and upper stage, as seen in Fig. 12.

4. At this stage, the data from all runs should collapse. Any variation seen is measurement error due to repeatability, positional accuracy of the CTS, small flow angularities in the test section, the presence of the upper stage strut, temperature gradients, etc. The variability is quantified for uncertainty quantification purposes and all runs are averaged, as seen in Fig 12 as a red dashed line.

5. The averaged data is then mirrored and transformed back to the vertical-plane axis system at nominal values. Figure 13 shows the symmetric data in the vertical-plane axis system. As expected, all runs collapse for the axial force coefficient, and the data is shown to be consistent between geometrical repeats for other forces and moments, in contrast with Fig. 10.

Another type of post-processing was required after analyzing repeat runs from Ares I-X testing and noticing axial force coefficient discrepancies at one particular condition that were much larger than the balance calibration error. This discrepancy is seen in Fig. 14. Some of the repeat runs exhibit high axial force at $X_{\text {sep }} / D=4.5$, and some exhibit low axial force at the same downstream position. This behavior was explained by examining the Schlieren videos, where it was found that the bow shock on the first stage vehicle interacts with the shocks emanating from the wake and induce a jump from a high drag state to a low drag state at the exact location where data was being taken $\left(X_{\text {sep }} / D=4.5, R_{\text {sep }} / D=1\right)$.

Figure 16 is an illustration of the shock interaction that induces a jump between the high and low drag configuration. Figure 17 is a Schlieren video screen capture that shows the slight but sudden change in shock angle due to the very localized interaction. Traversing downstream, the shock becomes suddenly shallower, reducing the drag on the first stage. Physical modeling was therefore implemented to include this effect in the axial force trend since none of the runs exhibited the jump from high to low drag. All only showed high or low drag. Extra artificial data points were created to perform this task, as seen in Fig. 15. The same procedure as described above was also applied to this type of data to force symmetry and consistency.

Another feature noticeable in this set of data is the first stage exhibiting uniformly lower drag when it is located directly behind the upper stage strut (e.g. run 1285 in Fig 14). These slightly corrupted runs was discarded and the standard post-processing prodedure allows for that gap in the data set to be filled.

\section{Stage separation testing lessons learned}

\section{A. CTS testing}

Captive trajectory testing is an extremely efficient way to operate when a large matrix of data points is required. It would not have been possible to acquire such a large scale database without such equipment. The system takes careful 
CAF FS
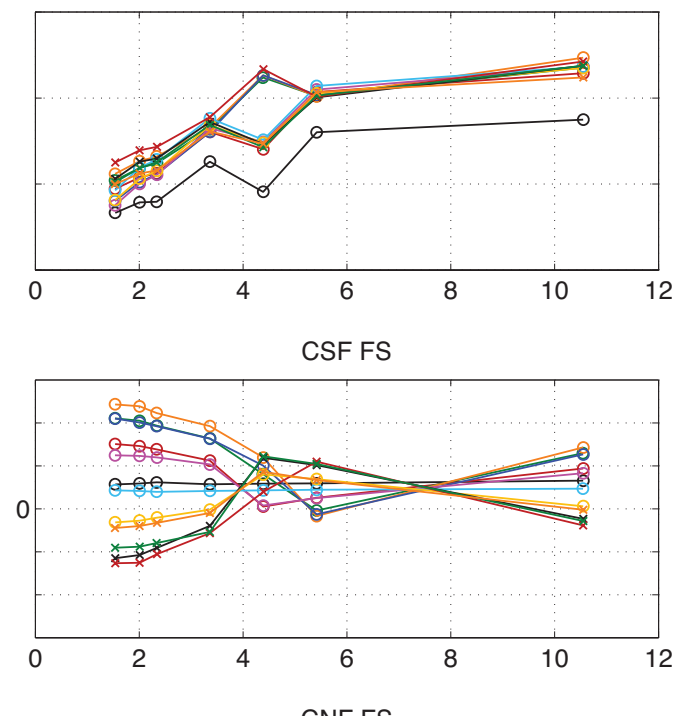

CNF FS

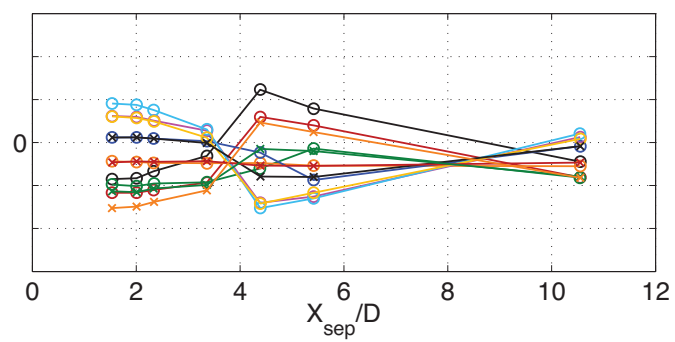

CRM FS
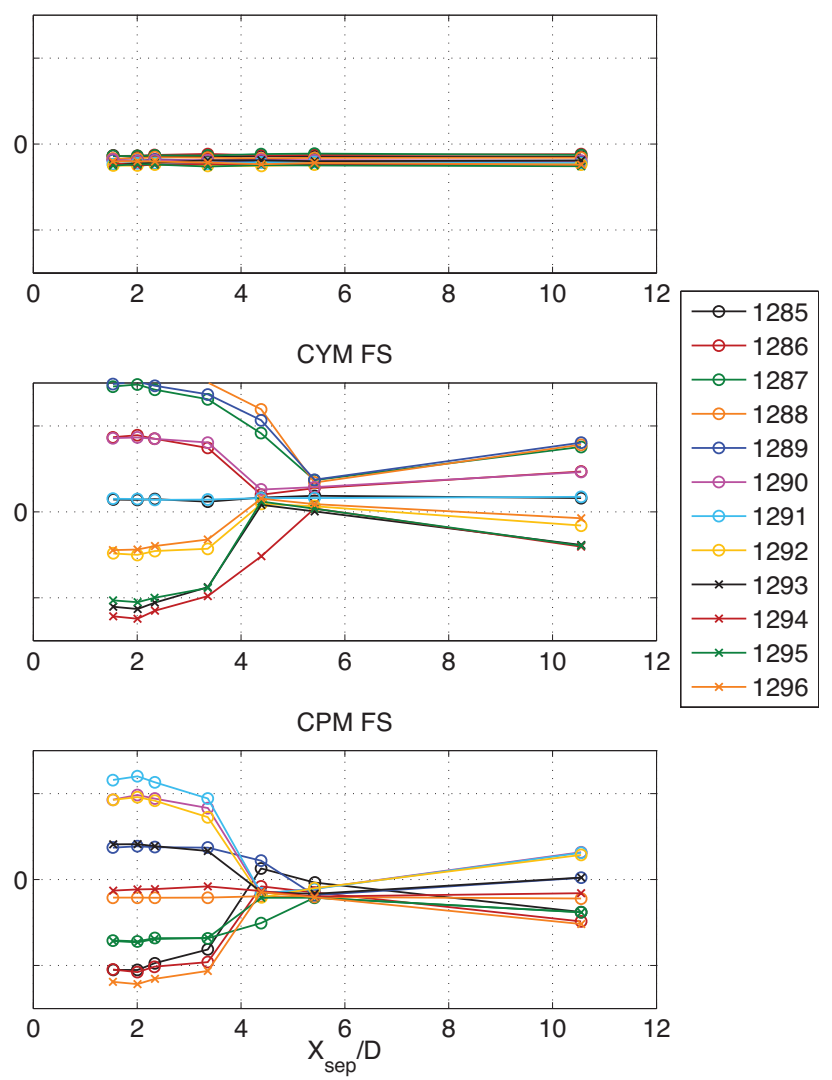

Figure 14. First stage force and moment data post-processing.
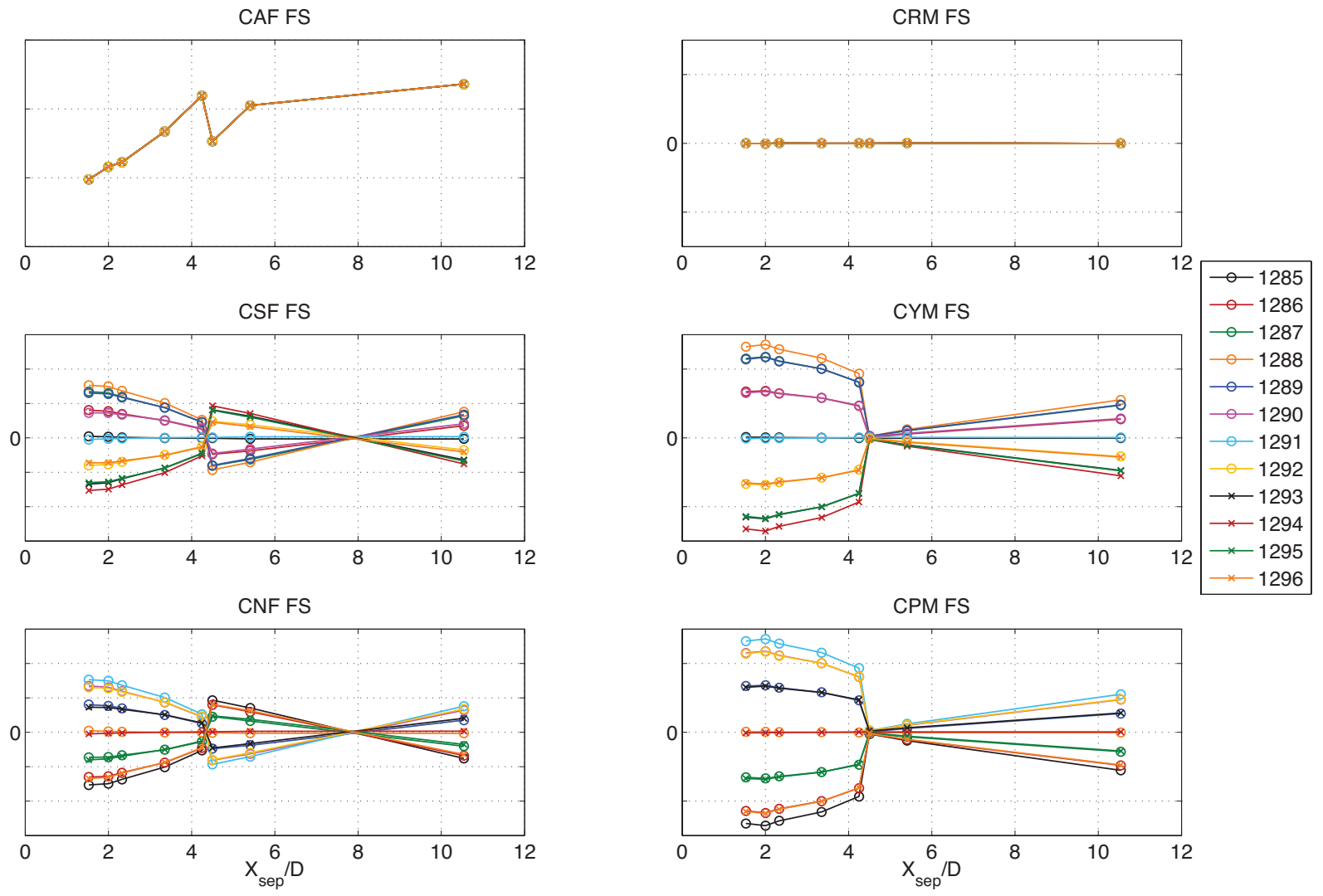

Figure 15. First stage force and moment data post-processing. 


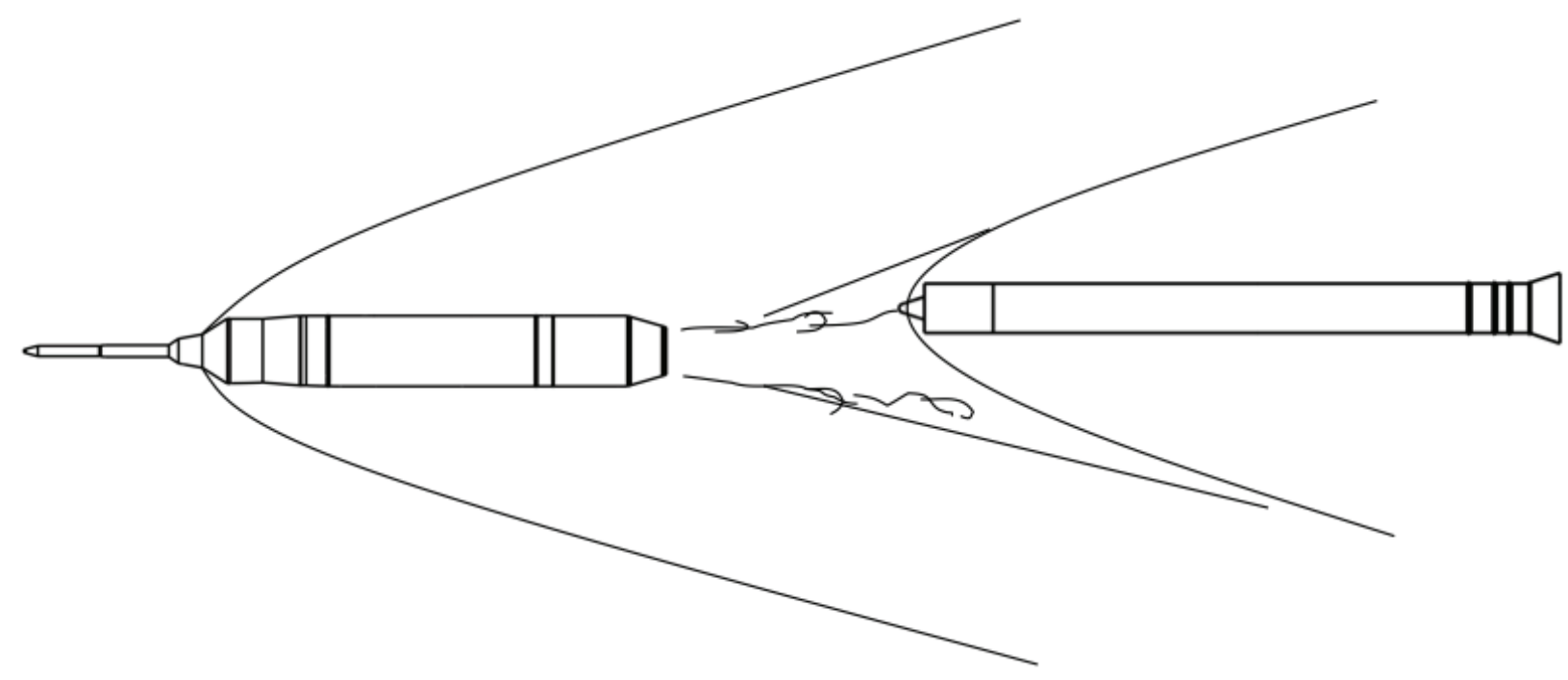

Figure 16. Schematic illustrating the wake shock interaction with the first stage bow shock, as seen in the Schlieren flow visualization.
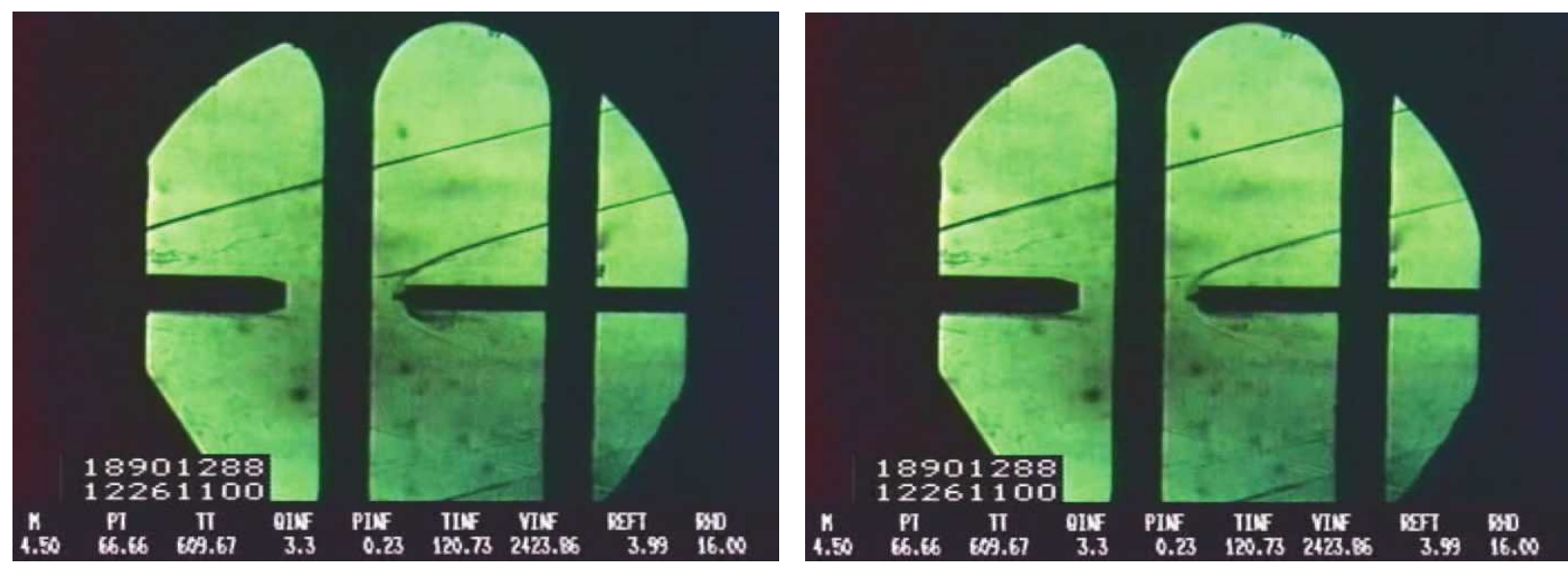

Figure 17. Schlieren pictures showing the small but sudden shock angle change exhibited on Ares I-X, at $R_{\text {sep }} / D=1$ and $X_{\text {sep }} / D=4.5$. At left is the high drag shock pattern and at right is the low drag pattern. 
and lengthy calibration and troubleshooting initially, however it is well worth the time invested. Since the system is automatically controlled is is important to have a very effective fouling system that prevents overloading of the balances in case of an erroneous displacement that could provoke a collision between the two models. The fouling system in place at the VKF Tunnel A is very efficient and, although several contacts occurred between the models during the test, the integrity of the balances was never in jeopardy and maximum loads were never reached in a steady sense.

\section{B. Pressure lag}

At the high supersonic Mach numbers where static pressure in the tunnel is very low, significant pressure lags can be experienced in the tubing when the length from the tap to the sensor (ESP or Kulite) is greater than 2 to 3 feet. The gage of the tubing also plays an important role, the smaller the tube diameter the larger the lag. This effect can be a problem when the data is taken continuously without leaving time for the pressure to propagate along the tubes and will induce a corrupted pressure reading. During a force and moment test, if the base and cavity pressures are lagging, then the base force correction will be corrupted as well, resulting in erroneous corrected axial force coefficients. It is then extremely difficult and impractical to correct for these kinds of errors a posteriori. Therefore much care needs to be taken when designing the experiment in estimating the potential lag induced by the length of the tubing. The solution to this problem is either to slow the pitching or rolling rate during runs or to shorten the tube length by moving the sensors as close as possible to the tap location. The ideal is to have the pressure sensors inside the model, however this was not an option with the small scale and little room inside the model. To investigate whether there is lag in the tubing, one can perform a continuous positive pitch run (e.g. $-10^{\circ}$ to $+10^{\circ}$ angle of attack) followed by a continuous negative pitch run $\left(e . g .+10^{\circ}\right.$ to $-10^{\circ}$ angle of attack). When plotting axial force coefficient corrected for base force as a function of angle of attack, if no lag is present, both curves should be equal, within measurement uncertainty.

\section{Temperature variations}

Temperatures in the tunnel can reach $200^{\circ} \mathrm{F}$, in which case the balance temperature can surpass $150^{\circ} \mathrm{F}$, which is a relatively large variation compared to ambient temperature where balance zeros are taken. An uncertainty is therefore introduced by the fact that the balance calibration is sensitive to temperature. Even though Langley balances are temperature compensated, the compensation method is only effective for small differences in temperature relative to the temperatures that are experienced in Tunnel A at the higher Mach numbers. Where possible it is always preferable to take balance zeros when the balance is hot. During this test, the first stage was mounted on the CTS system and remained in the test section during the whole time, it was therefore difficult to take balance zeros at regular intervals since bringing the flow down and back up can be very expensive and risky at certain conditions. However, data points were taken at regular intervals at a safe position when the upper stage was retracted in the injection tank to monitor any shift in balance zeros, which could, if present, corrupt the data. The upper stage was retracted at regular intervals, it was therefore more practical to take balance zeros very regularly and monitor balance zero shifts. In designing the experiment, great care should be taken to ensure that balance monitoring data points and zeros will be taken very often.

\section{Fine resolution sweep investigation}

A short amount of time at the beginning of the test should be spent performing fine resolution sweeps to detect any sharp gradients in the trends before deciding on the final increments chosen to be performed for the rest of the test. A sharp gradient was noticed during post-processing on the Ares I-X model at one particular condition, where data happened to be taken. Without taking data at the exact condition, the dynamic event would have been missed. When the time permits, such an initial investigation would ensure that this kind of phenomena is not overlooked.

\section{E. Tunnel operations}

Initially, two shifts per day were dedicated to running the test. Most of the first shift and part of the second were spent performing system and instrumentation checks and getting the tunnel to conditions, which showed to be a very inefficient mode of operations. It was therefore decided to revert to three-shift operations where the data could be taken continuously without interruption once the tunnel was brought online. A great amount of time and funds were saved by running the tunnel in a 3-shift rather than 2-shift operation mode. 


\section{Conclusion}

The AEDC VKF Tunnel A facility and the unique capabilities it offers in terms of advanced testing techniques was crucial in obtaining the high quality data that is used to create a high fidelity stage separation aerodynamic databases for the Ares I-X flight test vehicle and the Ares I crew launch vehicle. The success of the Ares I-X flight test stage separation event can be in part attributed to the quality and amount of aerodynamic data that was gathered during this wind tunnel test. Many lessons were learned in accomplishing this work and precious expertise in the area of captive trajectory testing was gained. Although the RoCS, BDM and BTM nozzle flows were not simulated during the test, many questions have been left unanswered as to the effect of jet interactions on the aerodynamics of the vehicle and RANS-type CFD has not provided validated results to address these issues. The experience gained during this poweroff stage separation test will be an advantage when investigating the effects of powered flight in a wind tunnel test.

\section{Acknowledgments}

The authors would like to recognize the whole test and project personnel at the AEDC VKF Tunnel A for their dedication to completing such a complex task with success. The data gathered at this facility has provided critical aerodynamic information to the Constellation program and in particular to the Ares I crew launch vehicle and Ares I-X flight test projects.

\section{References}

\footnotetext{
${ }^{1}$ Boudreau, A. H., "Performance and Operational Characteristics of AEDC/VKF Tunnels A, B, and C," AEDC-TR-80-48, 1981.

${ }^{2}$ Erickson, G. E., "0.01-Scale CLV DAC-2A Force and Moment Model Testing in the NASA Langley Research Center Unitary Plan Wind Tunnel, UPWT Tests 1968/1813," Ares-AD-TA-0004, 2007. 2011.

${ }^{3}$ Pinier, J. T., "Ares I Aerodynamic Testing at the Boeing Polysonic Wind Tunnel," 49th AIAA Aerospace Sciences Meeting, Orlando, Florida,

4"Calibration and Use of Internal Strain-Gage Balances with Application to Wind Tunnel Testing," AIAA Recommended Practice, AIAA R091-2003, 2003.

${ }^{5}$ Hemsch, M. J., Hanke, J. L., and Houlden, H. P., “Quality Assurance and Uncertainty Quantification for Ares I A103 Ascent Aero Data Base," Ares-AD-TA-0011, 2008.
} 